\title{
Determination of accurate theoretical values for thermodynamic properties in bulk metallic glasses
}

\author{
Pei-You Li · Gang Wang • Ding Ding • \\ Jun Shen
}

Received: 15 July 2013/Accepted: 23 September 2013/Published online: 31 October 2013

(c) Shanghai University and Springer-Verlag Berlin Heidelberg 2013

\begin{abstract}
Deviation values of specific heat difference $\Delta C_{\mathrm{p}}$, the Gibbs free energy difference $\Delta G$, enthalpy difference $\Delta H$, and entropy difference $\Delta S$ between the supercooled liquid and corresponding crystalline phase produced by the linear, hyperbolic, and Dubey's expressions of $\Delta C_{\mathrm{p}}$ and the corresponding experimental values are determined for sixteen bulk metallic glasses (BMGs) from the glass transition temperature $T_{\mathrm{g}}$ to the melting temperature $T_{\mathrm{m}}$. The calculated values produced by the hyperbolic expression for $\Delta C_{\mathrm{p}}$ most closely approximate experimental values, indicating that the hyperbolic $\Delta C_{\mathrm{p}}$ expression can be considered universally applicable, compared to linear and Dubey's expressions for $\Delta C_{\mathrm{p}}$, which are accurate only within a limited range of conditions. For instance, Dubey's $\Delta C_{\mathrm{p}}$ expression provides a good approximation of actual experimental values within certain conditions (i.e., $\xi=\Delta C_{\mathrm{p}}^{\mathrm{g}} / \Delta C_{\mathrm{p}}^{\mathrm{m}}<2$, where $\Delta C_{\mathrm{p}}^{\mathrm{g}}$ and $\Delta C_{\mathrm{p}}^{\mathrm{m}}$ represent the specific heat difference at temperatures $T_{\mathrm{g}}$ and $T_{\mathrm{m}}$, respectively).
\end{abstract}

Keywords Bulk metallic glass (BMG) $\cdot$ Specific heat $\cdot$ Linear expression · Hyperbolic expression

\footnotetext{
P.-Y. Li · J. Shen

School of Materials Science and Engineering, Harbin Institute of Technology, Harbin 150001, People's Republic of China

e-mail: junshen@hit.edu.cn

G. Wang $(\bowtie) \cdot$ D. Ding

Laboratory for Microstructures, Shanghai University, Shanghai 200444, People's Republic of China

e-mail: g.wang@shu.edu.cn
}

\section{Introduction}

Due to the presence of a large supercooled liquid region, bulk metallic glasses (BMGs) usually exhibit high thermal stability against crystallization. As a result, a large range of experimental time and temperatures for nucleation and crystalline growth processes exist in metallic glass forming melts. Characterization of the three thermodynamic parameters including Gibbs free energy difference $\Delta G$, entropy difference $\Delta S$, and enthalpy difference $\Delta H$, are important in evaluation of nucleation and crystal growth processes in BMGs between the supercooled liquid and corresponding crystalline phases $[1,2]$. Nucleation rates have been shown to have an exponential dependence on $\Delta G$ [3], acting as a driving force of nucleation. When $\Delta G$ is small, the critical nucleation work is improved, and nucleation rates are reduced [4]. As a result, the glass forming ability (GFA) of these materials is improved. The values of $\Delta G, \Delta S$, and $\Delta H$ are routinely calculated by measuring changes in the specific heat difference, $\Delta C_{\mathrm{p}}$, between the supercooled liquid and corresponding crystalline phases across a range of temperatures.

The metastable nature of supercooled liquids, however, makes accurate experimental values for $\Delta C_{\mathrm{p}}$ difficult to determine [5]. Thus, most $\Delta C_{\mathrm{p}}$ values for the supercooled liquid regions of various BMGs are only rough approximations generated by fitting limited experimental data to the melting temperature, $T_{\mathrm{m}}$, in the vicinity of the glass transition temperature $T_{\mathrm{g}}$. Because the accurate specific heat data in the supercooled region are notably absent, the functional dependences of $\Delta G, \Delta S$, and $\Delta H$ on temperature are generally estimated theoretically [5]. Several models for calculating $\Delta G, \Delta S$, and $\Delta H$ values have been previously proposed based on different expressions for $\Delta C_{\mathrm{p}}$ [6-14]. 
In these expressions, Thompson et al. [12] and Hoffman et al. [13] assumed that $\Delta C_{\mathrm{p}}$ was constant with temperature. Whereas Mondal et al. [10] and Patel et al. [11] suggested that $\Delta C_{\mathrm{p}}$ value depended linearly or hyperbolically on temperature, respectively. Each of these expressions, however, is deduced strictly from experimental data [6, 10-14] without theoretical support.

Recently, Dubey et al. [7, 8] proposed a theoretical expression for $\Delta C_{\mathrm{p}}$ based on the hole theory of the liquid state, thus calculating more accurate values for $\Delta G, \Delta H$, and $\Delta S$ from experimental results collected among the temperature range from $T_{\mathrm{g}}$ to $T_{\mathrm{m}}$ in the $\mathrm{Zr}_{57} \mathrm{Cu}_{15.4} \mathrm{Ni}_{12.6} \mathrm{Al}_{10} \mathrm{Nb}_{5}$ BMG [8]. Furthermore, a hyperbolic expression for $\Delta C_{\mathrm{p}}$ was deduced that provided an optimal mathematical model for elucidating GFA based on the theoretical expression for $\Delta C_{\mathrm{p}}$ proposed by Dubey et al. [7, 8].

According to the hyperbolic expression for $\Delta C_{\mathrm{p}}$ based on the hole theory of the liquid state [15], the current study further deduced a linear expression for $\Delta C_{\mathrm{p}}$. The values of $\Delta G, \Delta H, \Delta S$ and for BMGs in the temperature range from $T_{\mathrm{g}}$ to $T_{\mathrm{m}}$ were calculated based on the hyperbolic, linear, and Dubey's expression for $\Delta C_{\mathrm{p}}$. Sixteen BMG materials [16-26] were selected as models for using in experimental evaluation of the accuracy of these 3 expressions for $\Delta C_{\mathrm{p}}$ (Dubey's, hyperbolic, linear). The deviations observed in thermodynamic parameters between experimental results and these three models [7, 8, 15] were comparatively evaluated.

\section{Expressions for the thermodynamic parameters $\Delta C_{\mathrm{p}}$, $\Delta G, \Delta S$, and $\Delta H$}

Since $\Delta G$ is vital to the study of GFA in BMGs, expressions for $\Delta C_{\mathrm{p}}$ used in the calculation of $\Delta G$ values are important. The authors [15] previously proposed a hyperbolic expression for $\Delta C_{\mathrm{p}}$ based on the hole theory of the liquid state $[7,8]$, shown as follows:

$$
\begin{aligned}
\Delta C_{\mathrm{p}} & =\Delta C_{\mathrm{p}}^{\mathrm{m}}\left(\sigma_{\mathrm{h}}-1+\left(2-\sigma_{\mathrm{h}}\right) \frac{T_{\mathrm{m}}}{T}\right) \\
& =\Delta C_{\mathrm{p}}^{\mathrm{m}}\left(\sigma_{\mathrm{h}}-1+\left(2-\sigma_{\mathrm{h}}\right) \frac{1}{1-\frac{\Delta T}{T_{\mathrm{m}}}}\right),
\end{aligned}
$$

where $\Delta C_{\mathrm{p}}^{\mathrm{m}}$ is the specific heat difference between the supercooled liquid and the corresponding crystalline phase at $T_{\mathrm{m}} ; \sigma_{\mathrm{h}}$ is a coefficient related to the hole formation energy in the hyperbolic express; $\Delta T$ is the degree of supercooling ( $\Delta T=T_{\mathrm{m}}-T$, where $T$ is the temperature). In BMG systems, the $T_{\mathrm{m}}-T$ values are smaller than $T_{\mathrm{m}}$ when $T$ is decreased from $T_{\mathrm{m}}$ to $T_{\mathrm{g}}$, suggesting that the value of $\Delta T / T_{\mathrm{m}}$ is less than one. In this case, it is reasonable to approximate that the hyperbolic term in Eq. (1) can be expanded using a Taylor series, as follows:

$\frac{T_{\mathrm{m}}}{T}=\frac{1}{1-\frac{\Delta T}{T_{\mathrm{m}}}}=1+\frac{\Delta T}{T_{\mathrm{m}}}+\left(\frac{\Delta T}{T_{\mathrm{m}}}\right)^{2}+\cdots+\left(\frac{\Delta T}{T_{\mathrm{m}}}\right)^{n}$,

thus producing the expression by neglecting a portion of the higher-order terms $(n>1)$,

$\Delta C_{\mathrm{p}}=\Delta C_{\mathrm{p}}^{\mathrm{m}}\left(3-\sigma_{1}-\left(2-\sigma_{\mathrm{l}}\right) \frac{T}{T_{\mathrm{m}}}\right)$,

where $\sigma_{1}$ is a coefficient related to the hole formation energy in the linear expression. Since the portion of the higher-order terms $(n>1)$ in Taylor's series, i.e., Eq. (2), is neglected, which can modify the coefficient of $\left(2-\sigma_{\mathrm{h}}\right)$ in Eq. (1), $\sigma_{1}$ is used to replace $\sigma_{\mathrm{h}}$. The linear expression of $\Delta C_{\mathrm{p}}$ shown in Eq.(3) is similar to the linear form of $\Delta C_{\mathrm{p}}=$ $A+B T$, where $A\left(A=\frac{T_{\mathrm{g}} \Delta C_{\mathrm{p}}^{\mathrm{m}}-T_{\mathrm{m}} \Delta C_{\mathrm{p}}^{\mathrm{g}}}{T_{\mathrm{g}}-T_{\mathrm{m}}}=\Delta C_{\mathrm{p}}^{\mathrm{m}}\left(3-\sigma_{\mathrm{l}}\right)\right)$ and $B$ $\left(B=\frac{\Delta C_{\mathrm{p}}^{\mathrm{g}}-\Delta C_{\mathrm{p}}^{\mathrm{m}}}{T_{\mathrm{g}}-T_{\mathrm{m}}}=\frac{\Delta C_{\mathrm{p}}^{\mathrm{m}}\left(\sigma_{1}-2\right)}{T_{\mathrm{m}}}\right)$ are the coefficients for linear expression, proposed by Patel et al. [11]. Evaluation of the parameter $\sigma_{1}$ also results in a method similar to that proposed by Dubey et al. [7, 8]. Since experimental values of $\Delta C_{\mathrm{p}}^{\mathrm{g}}$ are usually measured in the vicinity of $T_{\mathrm{g}}$, the $\Delta C_{\mathrm{p}}^{\mathrm{m}}$ value can be employed in conjunction with Eq. (3) to yield

$\sigma_{1}=2+\frac{1-\xi}{1-T_{\mathrm{rg}}}$,

where $T_{\mathrm{rg}}=T_{\mathrm{g}} / T_{\mathrm{m}}$ is the reduced glass transition temperature; and $\xi=\Delta C_{\mathrm{p}}^{\mathrm{g}} / \Delta C_{\mathrm{p}}^{\mathrm{m}}$, where $\Delta C_{\mathrm{p}}^{\mathrm{g}}$ is the specific heat difference between the supercooled liquid and the corresponding crystalline phase at $T_{\mathrm{g}}$.

$\Delta G, \Delta H$ and $\Delta S$ are the differential values between the supercooled liquid and the corresponding crystalline phase, which can be expressed as

$\Delta H=\Delta H_{\mathrm{m}}-\int_{T}^{T_{\mathrm{m}}} \Delta C_{\mathrm{p}} \mathrm{d} T$

and

$\Delta S=\Delta S_{\mathrm{m}}-\int_{T}^{T_{\mathrm{m}}} \frac{\Delta C_{\mathrm{p}}}{T} \mathrm{~d} T$,

$\Delta G=\Delta H-T \Delta S$,

where $\Delta H_{\mathrm{m}}$ is the enthalpy of fusion, and $\Delta S_{\mathrm{m}}=\Delta H_{\mathrm{m}} / T_{\mathrm{m}}$ is the entropy of fusion. Substituting Eq. (3) into Eqs. (5)(7), the novel expressions for $\Delta H, \Delta S$ and $\Delta G$ can be obtained as 
Table 1 Thermodynamic parameters for evaluation of $\Delta G, \Delta H$, and $\Delta S$ in the 16 BMGs

\begin{tabular}{|c|c|c|c|c|c|c|c|c|c|}
\hline Alloys & $\begin{array}{l}A /\left(\mathrm{J} \cdot \mathrm{mol}^{-1} .\right. \\
\left.\mathrm{K}^{-2}\right)\end{array}$ & $\begin{array}{l}B /\left(\mathrm{J} \cdot \mathrm{mol}^{-1} .\right. \\
\left.\mathrm{K}^{-3}\right)\end{array}$ & $\begin{array}{l}C /\left(\mathrm{J} \cdot \mathrm{mol}^{-1} .\right. \\
\left.\mathrm{K}^{-2}\right)\end{array}$ & $T_{\mathrm{g}} / \mathrm{K}$ & $T_{\mathrm{m}} / \mathrm{K}$ & $T_{\mathrm{rg}}$ & $\begin{array}{l}\Delta H_{\mathrm{m}} /(\mathrm{kJ} \\
\left.\mathrm{mol}^{-1}\right)\end{array}$ & $\begin{array}{l}\Delta C_{\mathrm{p}}^{\mathrm{m}} /\left(\mathrm{J} \cdot \mathrm{mol}^{-1}\right. \\
\left.\mathrm{K}^{-1}\right)\end{array}$ & $\begin{array}{l}\Delta C_{\mathrm{p}}^{\mathrm{g}} /\left(\mathrm{J} \cdot \mathrm{mol}^{-1}\right. \\
\left.\mathrm{K}^{-1}\right)\end{array}$ \\
\hline $\mathrm{La}_{62} \mathrm{Al}_{14} \mathrm{Cu}_{24}[16]$ & 0.03071 & $4.16 \times 10^{5}$ & $-1.49 \times 10^{-5}$ & 401 & 673 & 0.60 & 6.835 & 14.840 & 12.510 \\
\hline $\mathrm{La}_{55} \mathrm{Al}_{25} \mathrm{Ni}_{20}$ [17] & 0.02190 & $1.24 \times 10^{6}$ & $-1.01 \times 10^{-5}$ & 491 & 712 & 0.69 & 7.477 & 12.940 & 13.460 \\
\hline $\mathrm{Cu}_{47} \mathrm{Ti}_{34} \mathrm{Zr}_{11} \mathrm{Ni}_{8}[18]$ & 0.01650 & $2.83 \times 10^{6}$ & $-6.82 \times 10^{-6}$ & 673 & 1114 & 0.60 & 11.300 & 12.187 & 14.257 \\
\hline $\mathrm{Zr}_{46} \mathrm{Cu}_{46} \mathrm{Al}_{8}$ [19] & 0.12850 & $4.61 \times 10^{6}$ & $-5.59 \times 10^{-6}$ & 715 & 979 & 0.73 & 8.035 & 13.490 & 16.410 \\
\hline $\mathrm{La}_{55} \mathrm{Al}_{25} \mathrm{Cu}_{10} \mathrm{Ni}_{5} \mathrm{Co}_{5}$ [17] & 0.02520 & $1.69 \times 10^{6}$ & $-1.18 \times 10^{-5}$ & 466 & 661 & 0.70 & 6.095 & 12.610 & 15.580 \\
\hline $\mathrm{La}_{62} \mathrm{Al}_{14}\left(\mathrm{Cu}_{5 / 6} \mathrm{Ag}_{1 / 6}\right)_{24}[16]$ & 0.03340 & $7.54 \times 10^{5}$ & $-3.04 \times 10^{-5}$ & 404 & 656 & 0.62 & 6.118 & 10.600 & 13.160 \\
\hline $\mathrm{Mg}_{65} \mathrm{Cu}_{25} \mathrm{Y}_{10}[20]$ & 0.01750 & $1.8 \times 10^{6}$ & $-1.02 \times 10^{-5}$ & 410 & 730 & 0.56 & 8.650 & 10.730 & 15.700 \\
\hline $\mathrm{Zr}_{57} \mathrm{Cu}_{15.4} \mathrm{Ni}_{12.6} \mathrm{Al}_{10} \mathrm{Nb}_{5}[18]$ & 0.01630 & $6.32 \times 10^{6}$ & $-8.37 \times 10^{-6}$ & 682 & 1091 & 0.63 & 9.400 & 13.130 & 20.810 \\
\hline $\begin{array}{l}\mathrm{Zr}_{46}\left(\mathrm{Cu}_{4.5 / 5.5} \mathrm{Ag}_{1 / 5.5}\right)_{46} \\
\quad \mathrm{Al}_{8}[19]\end{array}$ & 0.01620 & $8.17 \times 10^{6}$ & $-2.08 \times 10^{-5}$ & 620 & 937 & 0.66 & 8.200 & 11.060 & 17.870 \\
\hline $\mathrm{Pt}_{57.3} \mathrm{Cu}_{14.6} \mathrm{Ni}_{5.3} \mathrm{P}_{22.8}[21]$ & 0.01010 & $5.77 \times 10^{6}$ & $-1.20 \times 10^{-5}$ & 488 & 776 & 0.63 & 11.400 & 10.190 & 26.280 \\
\hline $\begin{array}{l}\mathrm{Zr}_{52.5} \mathrm{Cu}_{17.9} \mathrm{Ni}_{14.6} \mathrm{Al}_{10} \\
\mathrm{Ti}_{5}[18]\end{array}$ & 0.00260 & $6.43 \times 10^{6}$ & $-16.8 \times 10^{-6}$ & 675 & 1072 & 0.63 & 8.200 & 7.520 & 19.830 \\
\hline $\begin{array}{l}\mathrm{Ti}_{36.89} \mathrm{Cu}_{43.87} \mathrm{Ni}_{9.36} \mathrm{Zr}_{9.88} \\
\quad[22]\end{array}$ & 0.02140 & $1.02 \times 10^{7}$ & $-0.97 \times 10^{-5}$ & 678 & 1093 & 0.62 & 10.949 & 8.400 & 27.920 \\
\hline $\mathrm{Ti}_{37.65} \mathrm{Cu}_{43.25} \mathrm{Ni}_{9.6} \mathrm{Zr}_{9.5}[22]$ & 0.00870 & $1.17 \times 10^{7}$ & $-9.25 \times 10^{-6}$ & 673 & 1097 & 0.61 & 11.040 & 8.150 & 27.510 \\
\hline $\begin{array}{l}\mathrm{Zr}_{41.2} \mathrm{Ti}_{13.8} \mathrm{Ni}_{10} \mathrm{Cu}_{12.5} \mathrm{Be}_{22.5} \\
\quad[23,24]\end{array}$ & 0.01620 & $8.17 \times 10^{6}$ & $-2.08 \times 10^{-5}$ & 620 & 937 & 0.66 & 8.200 & 6.220 & 23.300 \\
\hline $\begin{array}{l}\mathrm{Zr}_{58.5} \mathrm{Cu}_{15.6} \mathrm{Ni}_{12.8} \mathrm{Al}_{10.3} \mathrm{Nb}_{2.8} \\
\quad[25]\end{array}$ & 0.01280 & $5.70 \times 10^{6}$ & $-1.37 \times 10^{-5}$ & 660 & 1083 & 0.61 & 8.700 & 2.655 & 15.550 \\
\hline $\mathrm{Pd}_{43} \mathrm{Ni}_{10} \mathrm{Cu}_{27} \mathrm{P}_{20}$ [26] & 0.03320 & $4.89 \times 10^{6}$ & $-5.00 \times 10^{-5}$ & 576 & 790 & 0.73 & 7.200 & 2.860 & 17.280 \\
\hline
\end{tabular}

$$
\begin{aligned}
\Delta H= & \Delta H_{\mathrm{m}}-\Delta C_{\mathrm{p}}^{\mathrm{m}}\left(\left(3-\sigma_{\mathrm{l}}\right)\left(T_{\mathrm{m}}-T\right)\right. \\
& \left.-\left(1-\frac{\sigma_{\mathrm{l}}}{2}\right) \frac{1}{T_{\mathrm{m}}}\left(T_{\mathrm{m}}^{2}-T^{2}\right)\right) \\
\Delta S= & \Delta S_{\mathrm{m}}-\Delta C_{\mathrm{p}}^{\mathrm{m}}\left(\frac{\sigma_{1}-2}{T_{\mathrm{m}}} \Delta T+\left(3-\sigma_{1}\right) \ln \frac{T_{\mathrm{m}}}{T}\right), \\
\Delta G= & \Delta S_{\mathrm{m}} \Delta T-\Delta C_{\mathrm{p}}^{\mathrm{m}}\left(\left(\sigma_{1}-2\right) \frac{\Delta T^{2}}{2 T_{\mathrm{m}}}\right. \\
& \left.+\left(3-\sigma_{\mathrm{l}}\right)\left(\Delta T-T \ln \frac{T_{\mathrm{m}}}{T}\right)\right) .
\end{aligned}
$$

Comparative studies were conducted on the expressions for $\Delta G, \Delta S$, and $\Delta H$ produced by the hyperbolic expression and Dubey's expression for $\Delta C_{\mathrm{p}}$ using the framework of the hole theory of the liquid state as a basis. This technique allowed for further characterization of the thermodynamic behaviors of BMGs. Based on the hyperbolic expression for $\Delta C_{\mathrm{p}}$, the expressions for $\Delta G, \Delta S$, and $\Delta H$, respectively, are [15]

$$
\begin{aligned}
\Delta G= & \Delta S_{\mathrm{m}} \Delta T-\Delta C_{\mathrm{p}}^{\mathrm{m}}\left(\left(3-\sigma_{\mathrm{h}}\right) \Delta T+\left(\left(3-\sigma_{\mathrm{h}}\right) T_{\mathrm{m}}\right.\right. \\
& \left.\left.-\left(\sigma_{\mathrm{h}}-1\right) \Delta T\right) \ln \frac{T_{\mathrm{m}}}{T}\right) \\
\Delta H= & \Delta H_{\mathrm{m}}-\Delta C_{\mathrm{p}}^{\mathrm{m}}\left(\left(\sigma_{\mathrm{h}}-1\right)\left(T_{\mathrm{m}}-T\right)+\left(2-\sigma_{\mathrm{h}}\right) T_{\mathrm{m}} \ln \frac{T_{\mathrm{m}}}{T}\right),
\end{aligned}
$$

$$
\Delta S=\Delta S_{\mathrm{m}}-\Delta C_{\mathrm{p}}^{\mathrm{m}}\left(\left(2-\sigma_{\mathrm{h}}\right) \frac{T_{\mathrm{m}}-T}{T}+\left(\sigma_{\mathrm{h}}-1\right) \ln \frac{T_{\mathrm{m}}}{T}\right)
$$

and

$\sigma_{\mathrm{h}}=1+\frac{1-T_{\mathrm{rg}} \xi}{1-T_{\mathrm{rg}}}$.

Based on the hole theory of the liquid state, Dubey et al. $[7,8]$ provided an expression for the $\Delta C_{\mathrm{p}}$ as

$\Delta C_{\mathrm{p}}=\Delta C_{\mathrm{p}}^{\mathrm{m}}\left(\frac{T_{\mathrm{m}}}{T}\right)^{2} \exp \left(-\sigma_{\mathrm{D}} \frac{\Delta T}{T}\right)$

where $\sigma_{\mathrm{D}}$ is a coefficient related to the hole formation energy in the Dubey's expression. Substituting Eq. (15) into Eqs. (5)-(7), the simplified Dubey's expressions for $\Delta G, \Delta H$ and $\Delta S$ are $[7,8]$

$\Delta G=\Delta S_{\mathrm{m}} \Delta T-\Delta C_{\mathrm{p}}^{\mathrm{m}} \frac{\Delta T^{2}}{2 T}\left(1-\sigma_{\mathrm{D}} \frac{\Delta T}{3 T}\right)$,

$\Delta H=\Delta H_{\mathrm{m}}-\Delta C_{\mathrm{p}}^{\mathrm{m}} T_{\mathrm{m}} \frac{\Delta T}{T}\left(1-\frac{\sigma_{\mathrm{D}} \Delta T}{2 T}\right)$

and

$\Delta S=\Delta S_{\mathrm{m}}-\Delta C_{\mathrm{p}}^{\mathrm{m}} \frac{\Delta T}{T}\left(1+\frac{\Delta T}{2 T}\right)\left(1-\frac{\sigma_{\mathrm{D}}}{2} \frac{\Delta T}{T} \frac{1+\frac{2 \Delta T}{3 T}}{1+\frac{\Delta T}{2 T}}\right)$. 


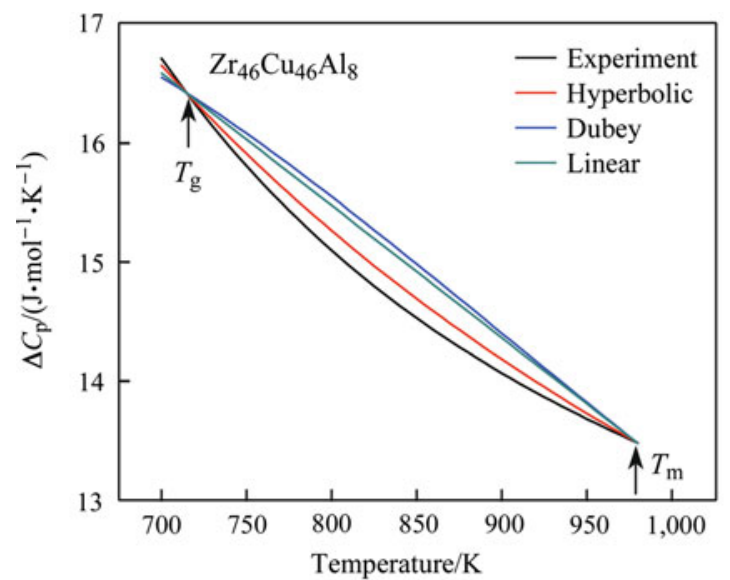

(a)

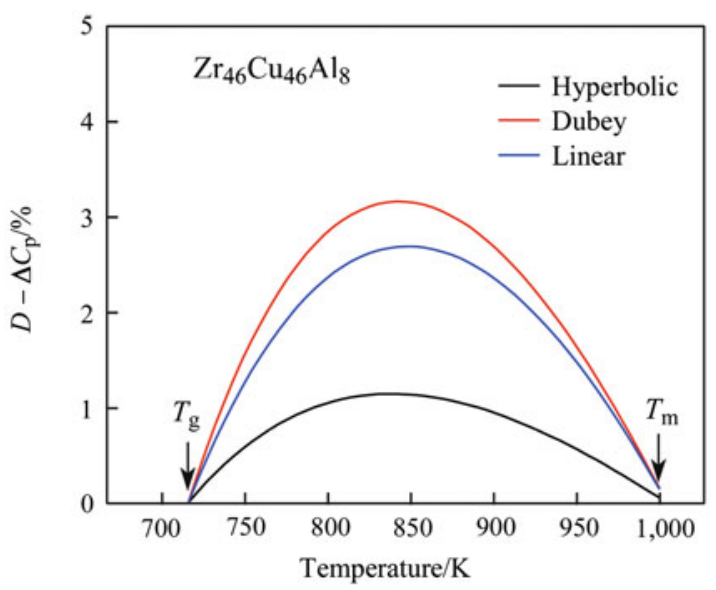

(c)

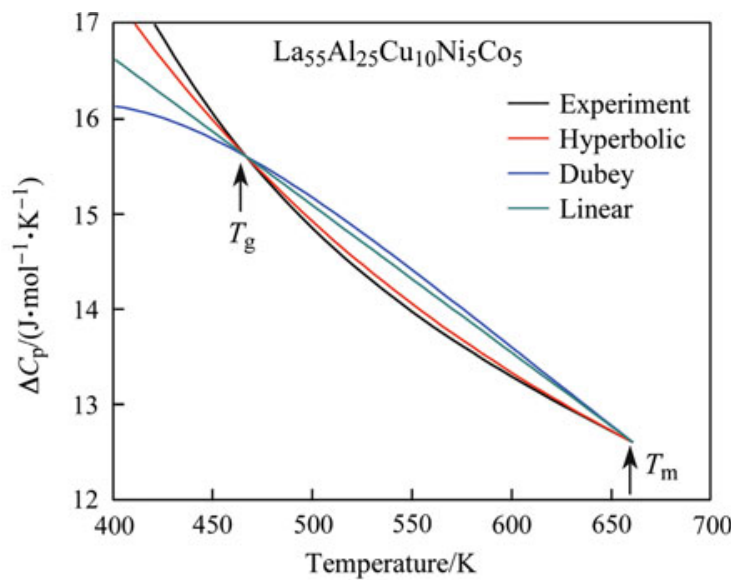

(b)

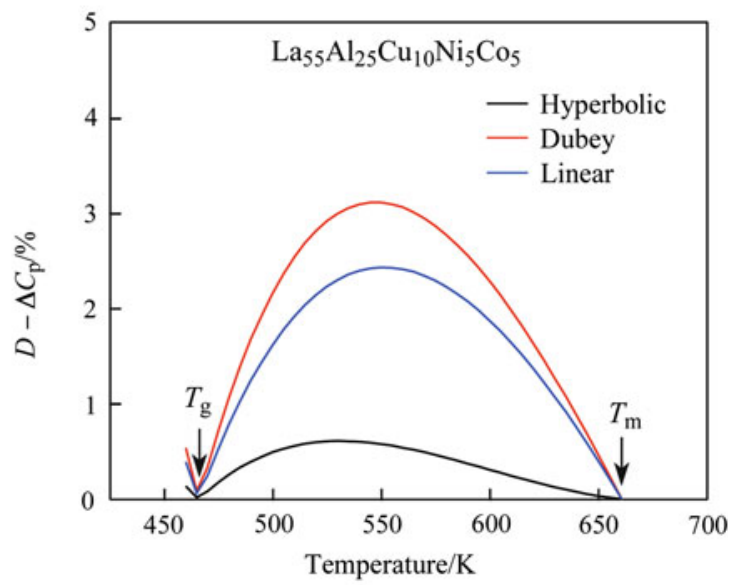

(d)

Fig. 1 Specific heat difference $\Delta C_{\mathrm{p}} \mathbf{a}, \mathbf{b}$, and the deviation values of $D-\Delta C_{\mathrm{p}} \mathbf{c}, \mathbf{d}$ as functions of temperature derived for 2 of 16 representative BMGs, $\mathrm{Zr}_{46} \mathrm{Cu}_{46} \mathrm{Al}_{8}$ and $\mathrm{La}_{55} \mathrm{Al}_{25} \mathrm{Cu}_{10} \mathrm{Ni}_{5} \mathrm{Co}_{5}$ alloys

The value $\sigma_{\mathrm{D}}$ is given by $[7,8]$

$\sigma_{\mathrm{D}}=\frac{T_{\mathrm{rg}}}{1-T_{\mathrm{rg}}} \ln \left(\frac{1}{T_{\mathrm{rg}}^{2} \xi}\right)$.

The deviation percentage $D$, between the theoretical calculated value and the experimental value can be expressed as

$D=\left|\frac{V(\bmod )-V(\exp )}{V(\exp )}\right|$,

where $V(\bmod )$ and $V(\exp )$ represent the calculated values and experimental values of $\Delta C_{\mathrm{p}}, \Delta G, \Delta H$ and $\Delta S$ respectively. As shown in Eqs. (4), (14), and (19), most of the BMG materials in this study exhibit $T_{\mathrm{rg}}$ values that can be considered to be a constant equal to 0.65 (discussed in detail in later sections). Thus the deviation values, $D$, for $\Delta C_{\mathrm{p}}, \Delta G, \Delta H$, and $\Delta S$ occurring between temperatures from $T_{\mathrm{g}}$ to $T_{\mathrm{m}}$ correlate with the $\sigma_{1}, \sigma_{\mathrm{h}}$ and $\sigma_{\mathrm{D}}$ values as well as the $\xi$ value.

\section{Deviation between theoretical model-based calculated and experimental values of $\Delta C_{\mathrm{p}}$ in BMGs}

The thermodynamic behavior of BMGs is studied using expressions for thermodynamic parameters $\Delta C_{\mathrm{p}}, \Delta G, \Delta S$, $\Delta H$, based on experimental results from 16 different BMGs. The values of $\Delta G, \Delta S$, and $\Delta H$ are calculated using experimentally measured $\Delta C_{\mathrm{p}}$ values, which can be expressed as [16-26]

$\Delta C_{\mathrm{p}}=A T+B T^{-2}+C T^{2}$,

where $A, B$, and $C$ are constant. These constants and parameters can be found in Refs. [16-26] and are summarized in Table 1 . The calculated $\Delta C_{\mathrm{p}}$ value, experimental $\Delta C_{\mathrm{p}}$ value, and deviation value between calculated and experimental values from $T_{\mathrm{g}}$ to $T_{\mathrm{m}}$ can be generated by Eqs. (1), (3), (15), (20), and (21). It is prolix that all figures of $\Delta C_{\mathrm{p}}, \Delta G, \Delta S, \Delta H$ are described for the 16 alloys. In consideration of the different $\xi$ values and alloy 


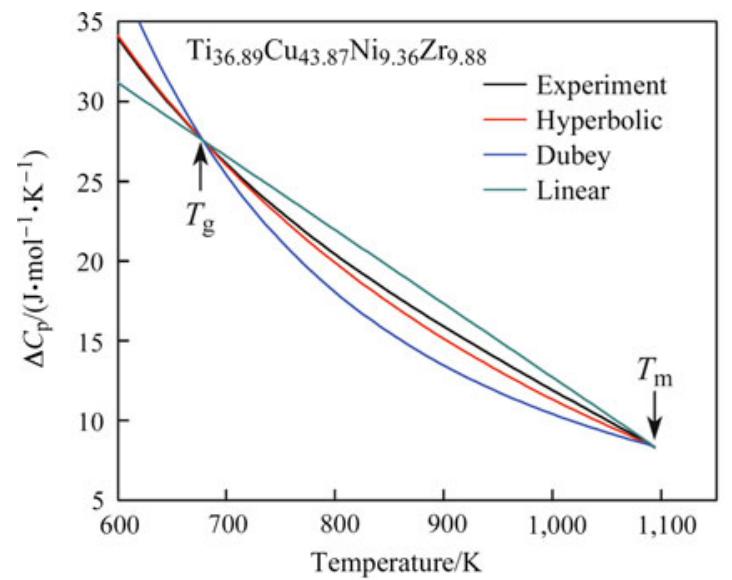

(a)

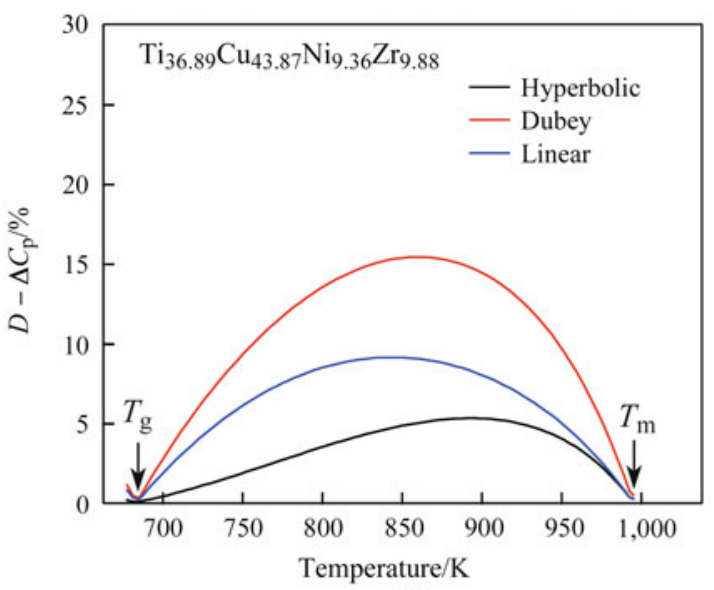

(c)

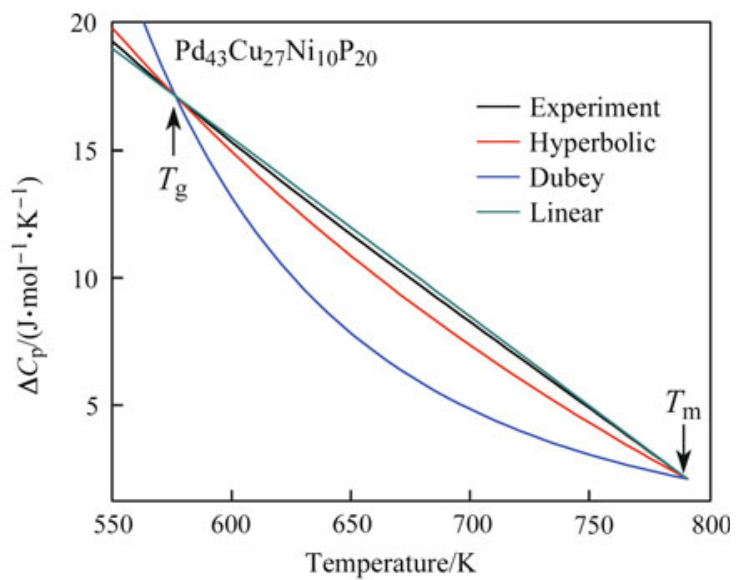

(b)

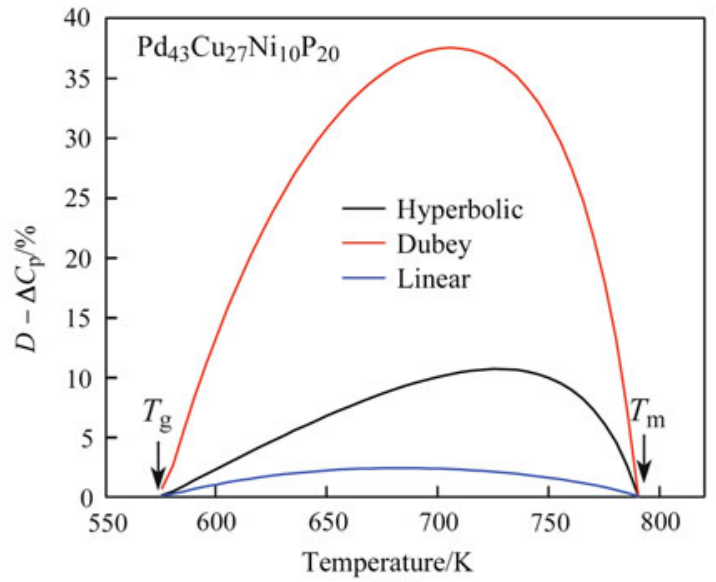

(d)

Fig. 2 Specific heat difference $\Delta C_{\mathrm{p}} \mathbf{a}, \mathbf{b}$, and the deviation values of $D-\Delta C_{\mathrm{p}} \mathbf{c}, \mathbf{d}$ as functions of temperature derived for 2 of 16 representative BMGs, $\mathrm{Ti}_{36.89} \mathrm{Cu}_{43.87} \mathrm{Ni}_{9.36} \mathrm{Zr}_{9.88}$ and $\mathrm{Pd}_{43} \mathrm{Ni}_{10} \mathrm{Cu}_{27} \mathrm{P}_{20}$ alloys

compositions in the present study, the 4 BMGs $\mathrm{Zr}_{46} \mathrm{Cu}_{46} \mathrm{Al}_{8} \quad$ [19], $\mathrm{La}_{55} \mathrm{Al}_{25} \mathrm{Cu}_{10} \mathrm{Ni}_{5} \mathrm{Co}_{5} \quad$ [17], $\mathrm{Ti}_{36.89} \mathrm{Cu}_{43.87} \mathrm{Ni}_{9.36} \mathrm{Zr}_{9.88}$ [22], and $\mathrm{Pd}_{43} \mathrm{Ni}_{10} \mathrm{Cu}_{27} \mathrm{P}_{20}$ [26] were representatively plotted in Figs. 1 and 2, respectively ( 2 materials per figure). These images are representative of results from all 16 BMGs (see Table 1).

Figures 1 and 2 show experimentally fitted $\Delta C_{\mathrm{p}}$ values and calculated values deduced from the hyperbolic, Dubey's, and linear expressions. Initially, the deviations in $\Delta C_{\mathrm{p}}$ for these $4 \mathrm{BMGs}$ increased, followed by an immediate reduction with further temperature increased from $T_{\mathrm{g}}$ to $T_{\mathrm{m}}$. The deviations in $\Delta C_{\mathrm{p}}$ achieved a maximum deviation value, $D_{\max }$, at an uncertain temperature in the range of $T_{\mathrm{g}}$ and $T_{\mathrm{m}}$. Notably, this value was achieved approximately at the midpoint between $T_{\mathrm{g}}$ and $T_{\mathrm{m}}$ in each sample. For $\mathrm{Zr}_{46} \mathrm{Cu}_{46} \mathrm{Al}_{8}$ and $\mathrm{La}_{55} \mathrm{Al}_{25} \mathrm{Cu}_{10} \mathrm{Ni}_{5} \mathrm{Co}_{5}$, the $D_{\text {max }}$ values of $\Delta C_{\mathrm{p}}, D_{\max }-\Delta C_{\mathrm{p}}$, from hyperbolic, linear, and Dubey's expressions were each smaller than $4 \%$, indicating that calculated values of $\Delta C_{\mathrm{p}}$ closely approximated experimental values, as compared with the $D_{\max }-\Delta C_{\mathrm{p}}$ values for $\mathrm{Ti}_{36.89} \mathrm{Cu}_{43.87} \mathrm{Ni}_{9.36} \mathrm{Zr}_{9.88}$ and $\mathrm{Pd}_{43} \mathrm{Ni}_{10} \mathrm{Cu}_{27} \mathrm{P}_{20}$ BMGs (see Fig. 2).

A comparison of the calculated and experimental values of $\Delta C_{\mathrm{p}}$ in BMGs is provided by the $D_{\max }-\Delta C_{\mathrm{p}}$ values for 16 BMGs (see Table 2). The relationship between $D_{\max }-$ $\Delta C_{\mathrm{p}}$ values and $\xi$ values for the 16 alloys is summarized in Fig. 3. In addition, $D_{\max }-\Delta C_{\mathrm{p}}$ values derived from the linear expression demonstrated a maximum value of $16 \%$ of the initial value, and the values derived from Dubey's expression increased with increasing $\xi$ value for $\xi>2$. Notably, the maximum value of Dubey's expression approached $38 \%$ of the initial value for a $\xi$ value of 6 . For the hyperbolic expression, $D_{\max }-\Delta C_{\mathrm{p}}$ values were generally less than $11 \%$ of the initial values. Cumulatively, these findings indicated that the hyperbolic expression for $\Delta C_{\mathrm{p}}$ fitted well with the experimental values compared with both linear and Dubey's expressions. When $\xi<2$, the $D_{\max }-\Delta C_{\mathrm{p}}$ derived from all 3 expressions was smaller 


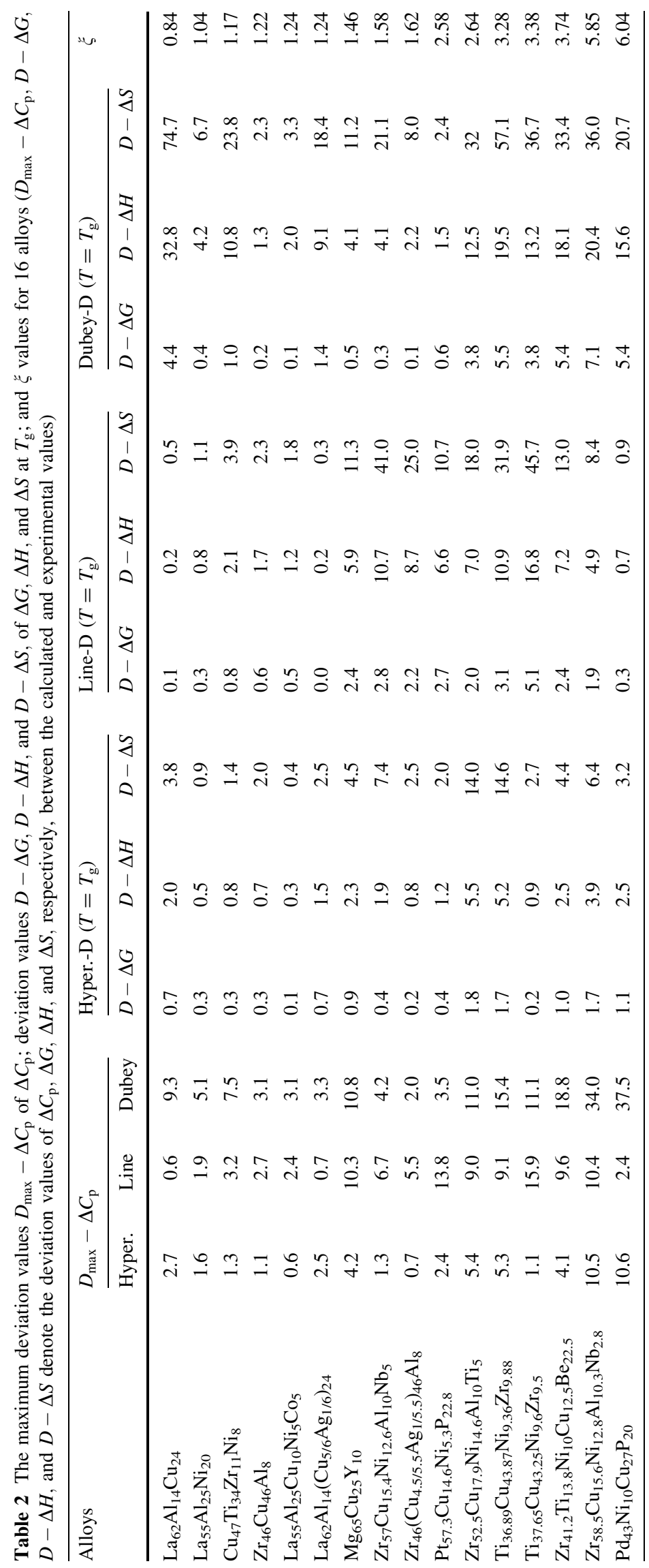




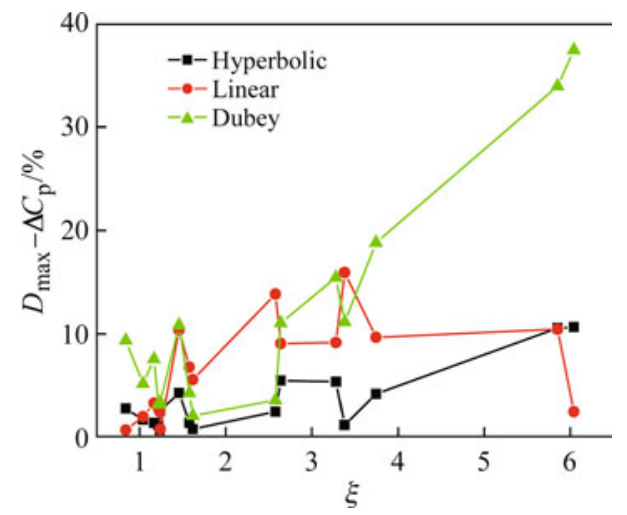

Fig. 3 Relationships between the maximal deviation values $D_{\max }-$ $\Delta C_{\mathrm{p}}$ (the maximum deviation of $\Delta C_{\mathrm{p}}$ between the calculated and experimental values), and the $\xi$ values for the 16 alloys in Table 2

than $11 \%$ of the initial value, suggesting that all 3 theoretical models were applicable.

\section{Deviations, calculated values, and experimental values of $\Delta G, \Delta S$, and $\Delta H$ in BMGs}

The deviation values $D$ of parameters $\Delta G, \Delta S, \Delta H, D-$ $\Delta G, D-\Delta S$, and $D-\Delta H$, respectively, between calculated and experimental values for 4 BMGs were determined. As shown in Figs. 4-7, the values of $D-\Delta G$, $D-\Delta H$, and $D-\Delta S$ exhibited maximum deviations at $T_{\mathrm{g}}$ in the temperature range from $T_{\mathrm{g}}$ to $T_{\mathrm{m}}$. A notable exception to this trend was the deviation value of $\Delta G$ from
Dubey's expression for $\Delta C_{\mathrm{p}}$ for $\mathrm{Zr}_{46} \mathrm{Cu}_{46} \mathrm{Al}_{8}$ (see Fig. $4 \mathrm{~d}$ ) and $\mathrm{Mg}_{65} \mathrm{Cu}_{25} \mathrm{Y}_{10}$ (not shown). Thus, deviation values for $\Delta G, \Delta S$, and $\Delta H$ at $T_{\mathrm{g}}$ could reasonably denote the degree of fit between $\Delta G, \Delta S$, and $\Delta H$ values in both calculated expressions and experimental results. $D-\Delta G, D-\Delta H$, and $D-\Delta S$ values at $T_{\mathrm{g}}$ for all 16 metallic glasses are listed in Table 2.

The $D-\Delta G, D-\Delta H$, and $D-\Delta S$ values at $T_{\mathrm{g}}$ and $\xi$ values for 16 BMGs are listed in Table 2 . The maximum $D-\Delta G$ values were achieved in the hyperbolic expression, whereas Dubey's and linear expression values for $\Delta C_{\mathrm{p}}$ were smaller than $8 \%$ of initial values, indicating the accuracy of calculated values using these 3 expressions for $\Delta G$ relative to experimental values. The maximum $D-$ $\Delta H$ and $D-\Delta S$ values achieved by the hyperbolic expression for $\Delta C_{\mathrm{p}}$ in $16 \mathrm{BMGs}$ were less than $10 \%$ and $15 \%$ of initial values (see Table 2), respectively. The maximum $D-\Delta H$ and $D-\Delta S$ values derived from linear and Dubey's expressions for $\Delta C_{\mathrm{p}}$ (see Table 2) presented bigger values of $16.8 \%$ and $45.7 \%$, respectively, compared with those derived from the hyperbolic expression. Thus, calculations for $\Delta G, \Delta H$, and $\Delta S$ values also suggested that the hyperbolic expression for $\Delta C_{\mathrm{p}}$ was the most accurate predictor of experimental values.

Results and analysis of $D-\Delta H$ and $D-\Delta S$ derived from Dubey's expression for $\Delta C_{\mathrm{p}}$ produced similar findings to those of $D-\Delta C_{\mathrm{p}}$ derived from Dubey's expression. The majority of $D-\Delta H$ and $D-\Delta S$ values derived from Dubey's expression for $\xi<2$ were very close to the $D-$ $\Delta H$ and $D-\Delta S$ values derived from the linear and

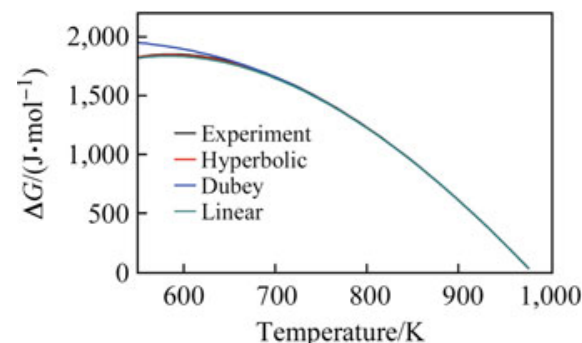

(a)

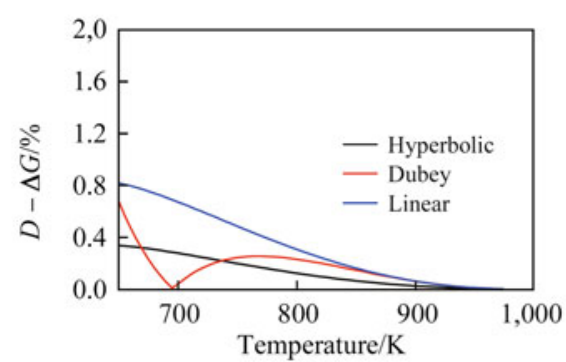

(d)

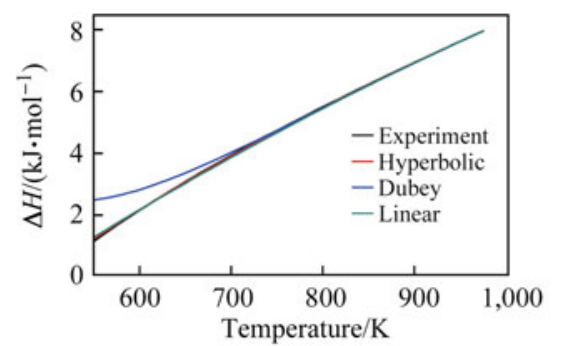

(b)

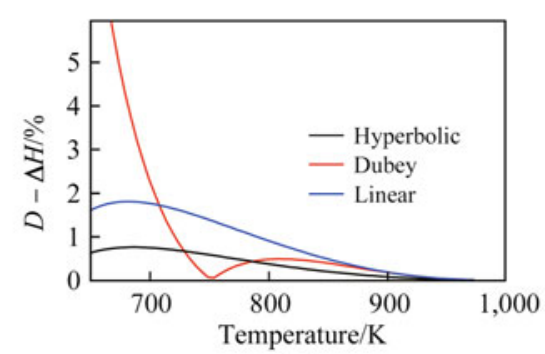

(e)

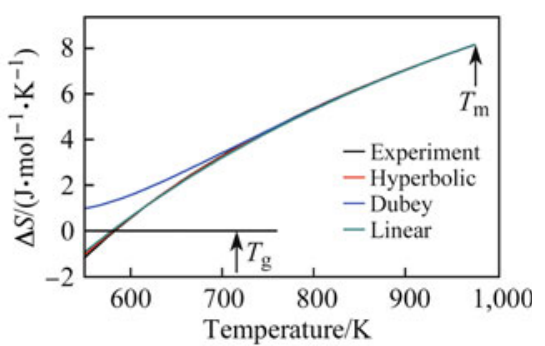

(c)

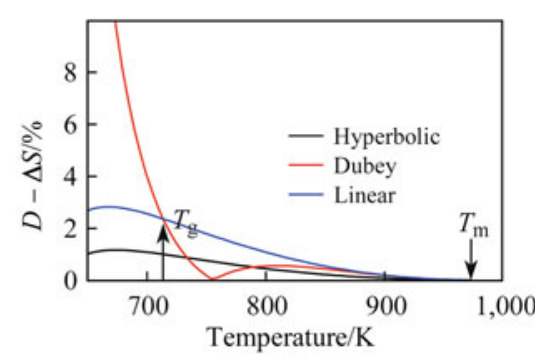

(f)

Fig. 4 Parameters $\Delta G \mathbf{a}, \Delta H \mathbf{b}$, and $\Delta S \mathbf{c}$ as well as deviation values $D-\Delta G \mathbf{d}, D-\Delta H \mathbf{e}$, and $D-\Delta S \mathbf{f}$ as functions of temperature derived for the $\mathrm{Zr}_{46} \mathrm{Cu}_{46} \mathrm{Al}_{8}$ alloy using reported experimental results and three different expressions 


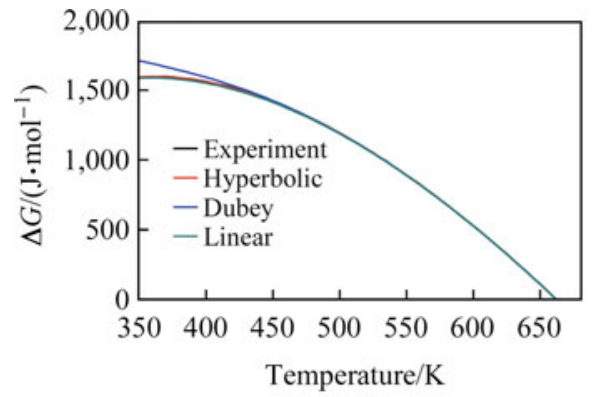

(a)

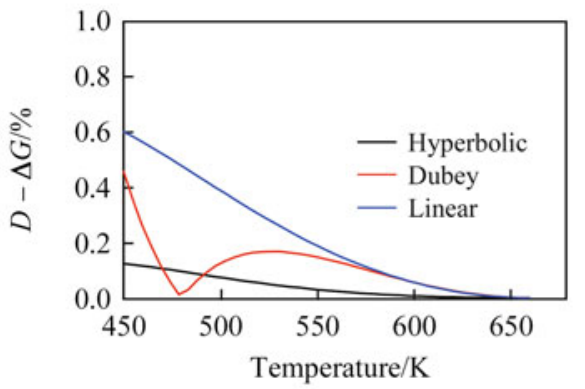

(d)

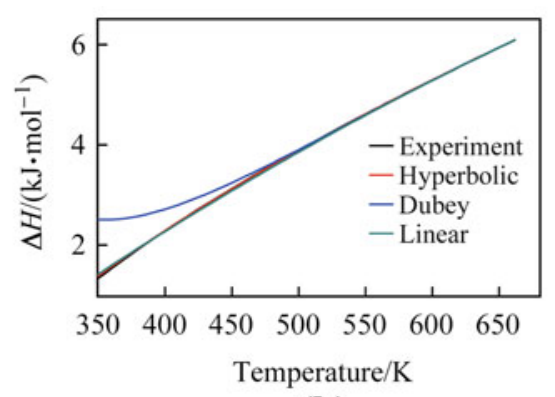

(b)

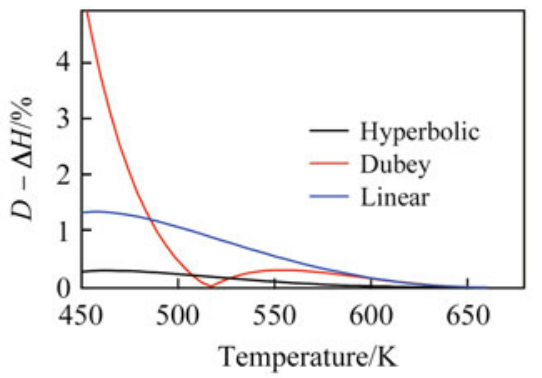

(e)

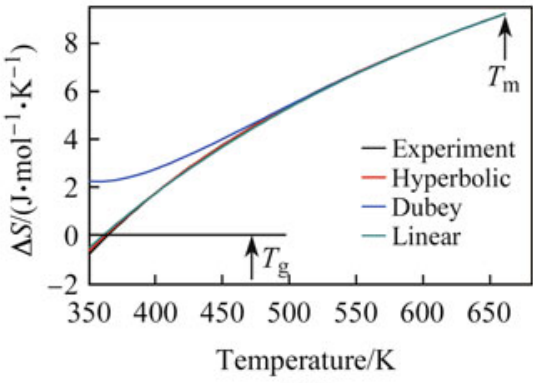

(c)

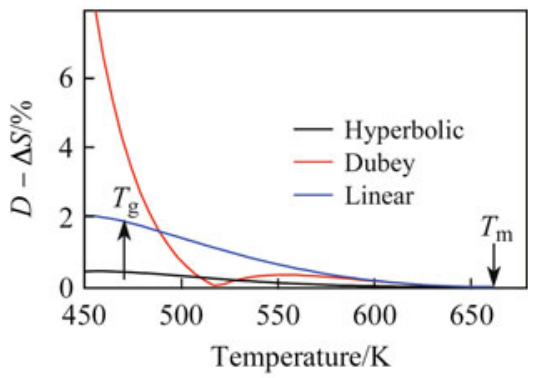

(f)

Fig. 5 Parameters $\Delta G \mathbf{a}, \Delta H \mathbf{b}$, and $\Delta S \mathbf{c}$ and deviation values $D-\Delta G \mathbf{d}, D-\Delta H \mathbf{e}$, and $D-\Delta S \mathbf{f}$ as functions of temperature derived for the $\mathrm{La}_{55} \mathrm{Al}_{25} \mathrm{Cu}_{10} \mathrm{Ni}_{5} \mathrm{Co}_{5}$ alloy using reported experimental results and 3 different expressions

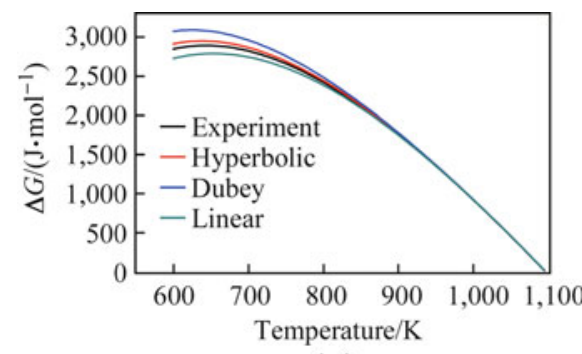

(a)

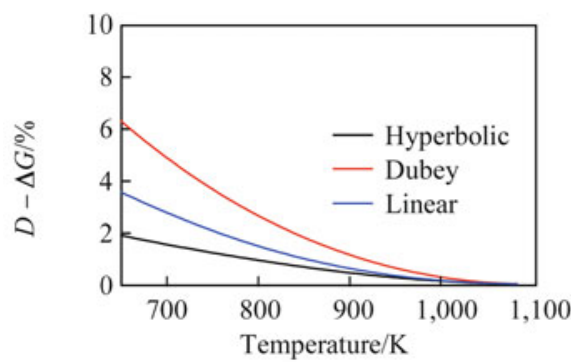

(d)

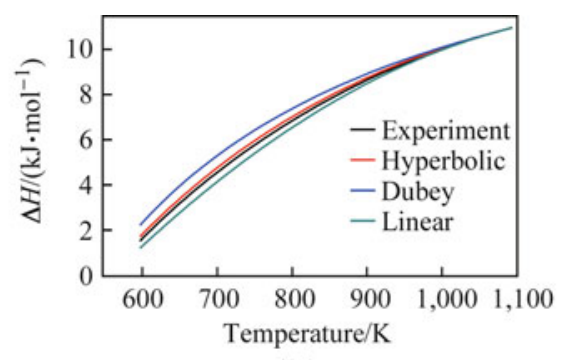

(b)

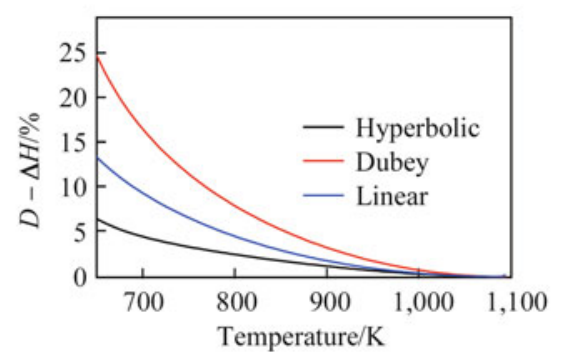

(e)

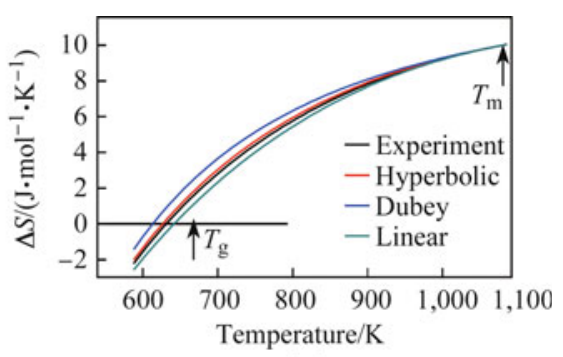

(c)

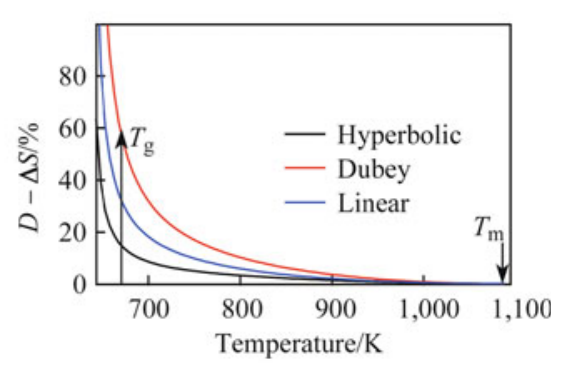

(f)

Fig. 6 Parameters $\Delta G \mathbf{a}, \Delta H \mathbf{b}$, and $\Delta S \mathbf{c}$ and deviation values $D-\Delta G \mathbf{d}, D-\Delta H \mathbf{e}$, and $D-\Delta S \mathbf{f}$ as functions of temperature derived for the $\mathrm{Ti}_{36.89} \mathrm{Cu}_{43.87} \mathrm{Ni}_{9.36} \mathrm{Zr}_{9.88}$ alloy using reported experimental results and 3 different expressions

hyperbolic expressions, suggesting that the difference between $D-\Delta H$ and $D-\Delta S$ values in each of the three expressions was very small for $\xi<2$ (see Table 2). The majority of $D-\Delta H$ and $D-\Delta S$ values derived from Dubey's expression for $\xi>2$ were much larger than the $D-\Delta H$ and $D-\Delta S$ values derived from the linear and hyperbolic expressions, suggesting that most $\Delta H$, and $\Delta S$ values derived from Dubey's expression did not accurately predict experimental values for $\xi>2$.

Thus, the hyperbolic expression for $\Delta C_{\mathrm{p}}$ represents are relatively universal expression, compared to the linear expression and Dubey's expression for $\Delta C_{\mathrm{p}}$ which are only 


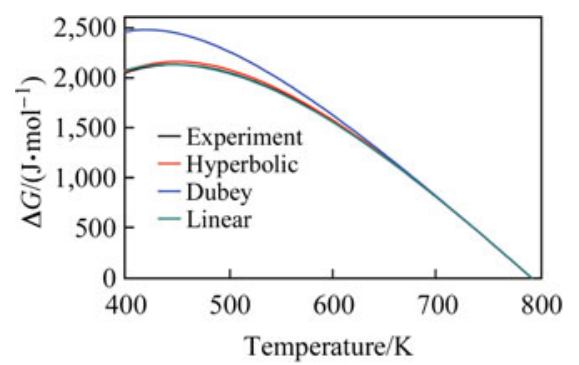

(a)

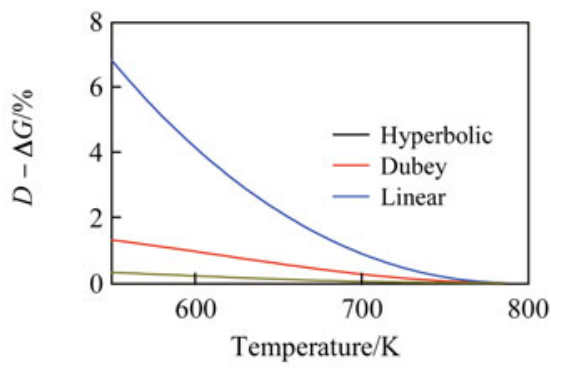

(d)

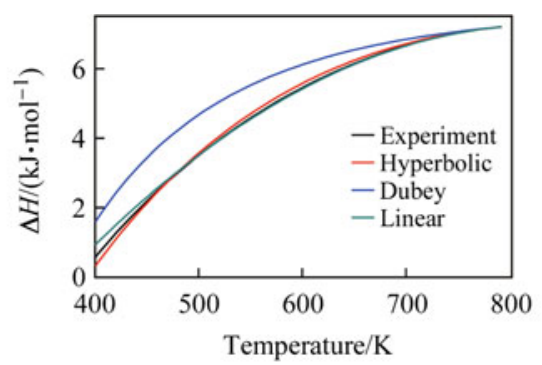

(b)

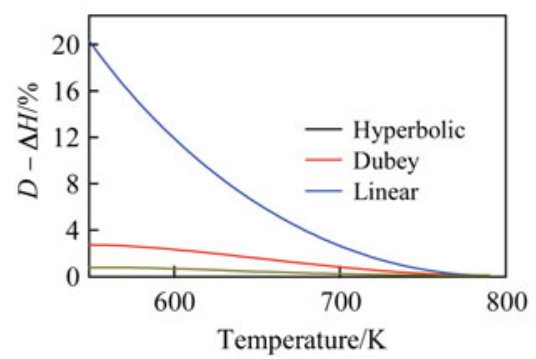

(e)

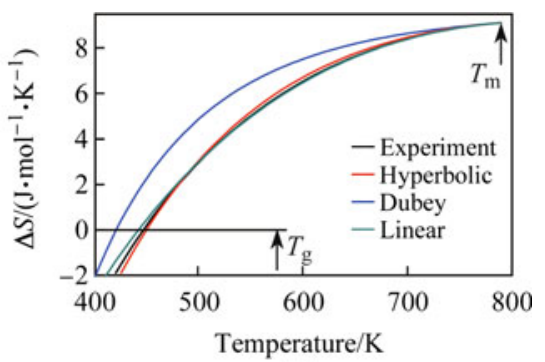

(c)

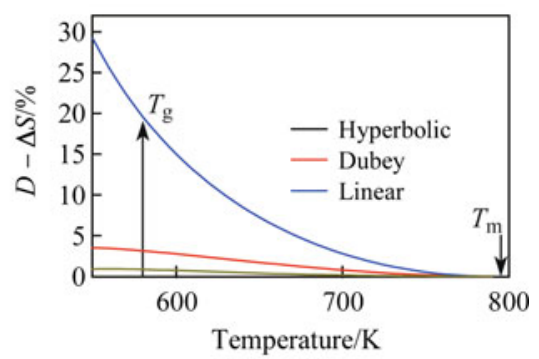

(f)

Fig. 7 Parameters $\Delta G \mathbf{a}, \Delta H \mathbf{b}$, and $\Delta S \mathbf{c}$ and deviation values $D-\Delta G \mathbf{d}, D-\Delta H \mathbf{e}$, and $D-\Delta S \mathbf{f}$ as functions of temperature derived for the $\mathrm{Pd}_{43} \mathrm{Ni}_{10} \mathrm{Cu}_{27} \mathrm{P}_{20}$ alloy using reported experimental results and 3 different expressions

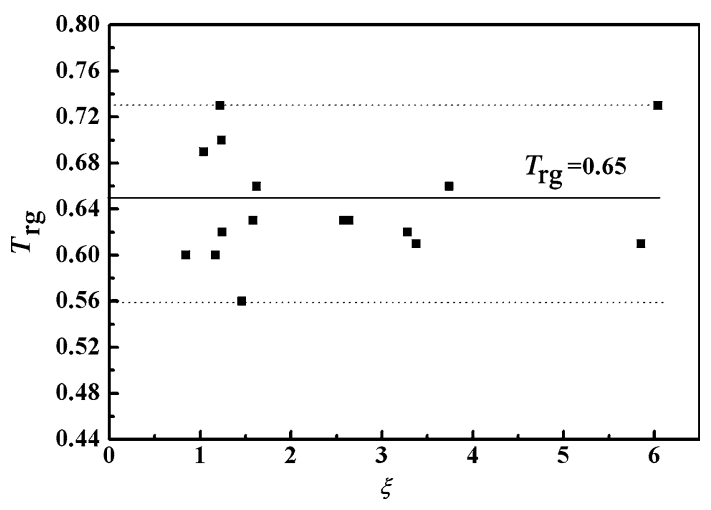

Fig. 8 Relationship between $T_{\mathrm{rg}}$ and $\xi$ values

accurate under certain conditions. Notably, experimental values more closely fit values produced by the linear expression for $\Delta C_{\mathrm{p}}$ than values produced by Dubey's expression for $\Delta C_{\mathrm{p}}$. Dubey's expression for $\Delta C_{\mathrm{p}}$ was, however, a good approximation of experimental values for $\xi<2$, though not for $\xi>2$.

\section{Discussion}

$D_{\max }$ between the calculated and experimental values for $\Delta C_{\mathrm{p}}, \Delta G, \Delta H$, and $\Delta S$ from $T_{\mathrm{g}}$ to $T_{\mathrm{m}}$ was found to be associated with the $\xi$ parameter according to Fig. 3 and Table 2. Equations (4), (14), and (19) showed that in addition to the effects of the $\xi$ parameter, $D$ values were also influenced by the $T_{\mathrm{rg}}$ values, which ranged from 0.56 to 0.73 and could be expressed as a function of the $\xi$ value (see Fig. 8). Thus, equidistant low, medium, and high $T_{\mathrm{rg}}$ values of $0.56,0.65$, and 0.73 were selected to further characterize the effect of $T_{\mathrm{rg}}$ on the value of $D$ (or $\left.D_{\max }\right)$. Figure 9a shows the relationship between the $\sigma_{\mathrm{h}}$, $\sigma_{\mathrm{D}}$, and $\sigma_{1}$ values and the $\xi$ values for $T_{\mathrm{rg}}$ values of 0.56 , 0.65 , and 0.73 .

For $\xi<2$, the change in the $3 \sigma_{\mathrm{h}}, \sigma_{\mathrm{D}}$, and $\sigma_{1}$ values with $T_{\mathrm{rg}}$ was negligible, suggesting that $\Delta C_{\mathrm{p}}, \Delta G, \Delta H$, and $\Delta S$ values calculated using different models were virtually identical (see Fig. 3 and Table 2). For $\xi>2$, however, the values of $\sigma_{\mathrm{h}}, \sigma_{\mathrm{D}}$, and $\sigma_{1}$ at the 3 different $T_{\mathrm{rg}}$ values revealed a decreasing trend. As $\xi$ values increased from 0.5 to $7, \sigma_{\mathrm{D}}$ values exhibited only small decreases, while larger decreases were exhibited by $\sigma_{\mathrm{h}}$ values. Moderate decreases in $\sigma_{1}$ values were observed in between those of $\sigma_{\mathrm{D}}$ and $\sigma_{\mathrm{h}}$ compared with $\sigma_{\mathrm{h}}, \sigma_{\mathrm{D}}$, and $\sigma_{1}$ values at $T_{\mathrm{rg}}=0.65$. Notably, this change can be neglected to simplify analysis.

Thus the majority of BMGs $T_{\mathrm{rg}}$ can be considered constant $\left(T_{\mathrm{rg}}=0.65\right)$. Figure $9 \mathrm{~b}$ demonstrates the relationship between $\sigma_{\mathrm{h}}, \sigma_{\mathrm{D}}$, and $\sigma_{1}$ values and the $\xi$ parameter at $T_{\mathrm{rg}}=0.65$. When $T_{\mathrm{rg}}=0.65$, the changes in $\sigma_{\mathrm{h}}, \sigma_{\mathrm{D}}$, and $\sigma_{1}$ values are revealed to be very large, leading to variation in the deviation values for $\Delta C_{\mathrm{p}}, \Delta G, \Delta H$, and $\Delta S$ between calculated and experimental values. As shown in Fig. 3 and Table 2, the $D_{\max }-\Delta C_{\mathrm{p}}$ values can be used to reveal the fit of $\Delta G, \Delta H$, and $\Delta S$ between the calculated and experimental values (see Fig. 3 and Table 2). Due to this observation, only $D_{\max }-\Delta C_{\mathrm{p}}$ values are discussed. 


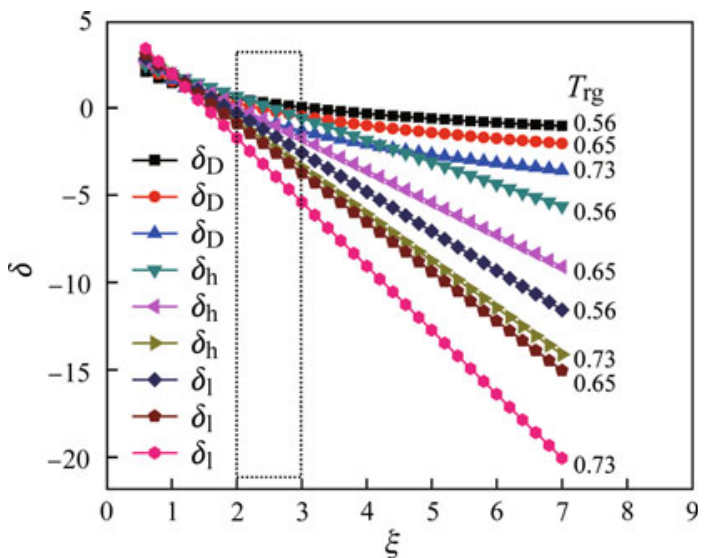

(a)

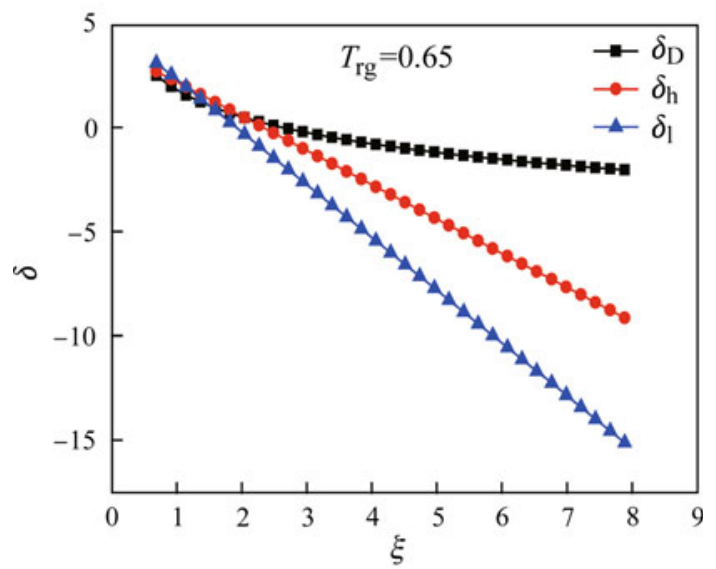

(b)

Fig. 9 Relationship between $\sigma_{\mathrm{h}}, \sigma_{\mathrm{D}}$, and $\sigma_{1}$, and $\xi$ values for different $T_{\text {rg }} \mathbf{a}$ and $T_{\text {rg }}=0.65 \mathbf{b}$

Graphs of $C_{\mathrm{p}}$ as a function of temperature when $\xi$ values equal to 2 and $3(\xi=2, \xi=3)$ are shown in Fig. 10a, in which $C_{\mathrm{p}}^{\mathrm{l}}$ and $C_{\mathrm{p}}^{\mathrm{s}}$ represent the heat capacity of the supercooled liquid and crystal, respectively. $C_{\mathrm{p}}^{\mathrm{l}}$ and $C_{\mathrm{p}}^{\mathrm{s}}$ values were derived by fitting the experimental data. Figure $10 \mathrm{~b}$ shows the $\Delta C_{\mathrm{p}}$ value evolution and temperature increases for $\xi$ values of 2 and 3 , where the $\xi$ parameter is the change rate of $\Delta C_{\mathrm{p}}^{\mathrm{s}}$ and $\Delta C_{\mathrm{p}}^{\mathrm{m}}$. In order to characterize the difference in $D_{\max }$ values produced by Dubey's expression and the hyperbolic expressions for $\Delta C_{\mathrm{p}}$ from $T_{\mathrm{g}}$ to $T_{\mathrm{m}}$, corresponding temperatures for $D_{\max }-\Delta C_{\mathrm{p}}$ values can be inferred.

Temperatures corresponding to the $D_{\max }-\Delta C_{\mathrm{p}}$ values for $\mathrm{Zr}_{46} \mathrm{Cu}_{46} \mathrm{Al}_{8}, \mathrm{La}_{55} \mathrm{Al}_{25} \mathrm{Cu}_{10} \mathrm{Ni}_{5} \mathrm{Co}_{5}, \mathrm{Ti}_{36.89} \mathrm{Cu}_{43.87} \mathrm{Ni}_{9.36} \mathrm{Zr}_{9.88}$, and $\mathrm{Pd}_{43} \mathrm{Ni}_{10} \mathrm{Cu}_{27} \mathrm{P}_{20}$ BMGs are generally between $T_{\mathrm{g}}$ and $T_{\mathrm{m}}$ (see Figs. 1 and 2). Thus $T_{\max }=0.5\left(T_{\mathrm{g}}+T_{\mathrm{m}}\right)$, where $T_{\max }$ is the hypothetical maximum temperature of $D_{\max }-\Delta C_{\mathrm{p}}$. All 16 studied BMGs also exhibit trends similar to those of the 4 representative materials shown (data not shown). $\Delta C_{\mathrm{p}}$ values calculated using the linear

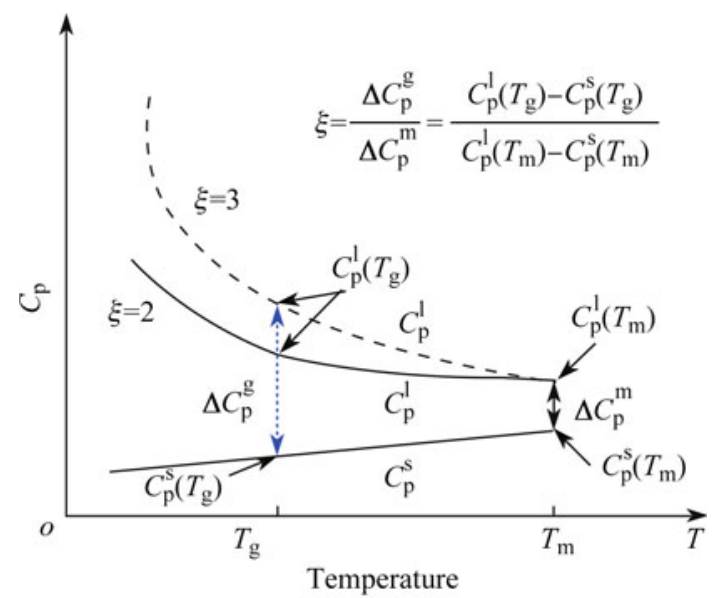

(a)

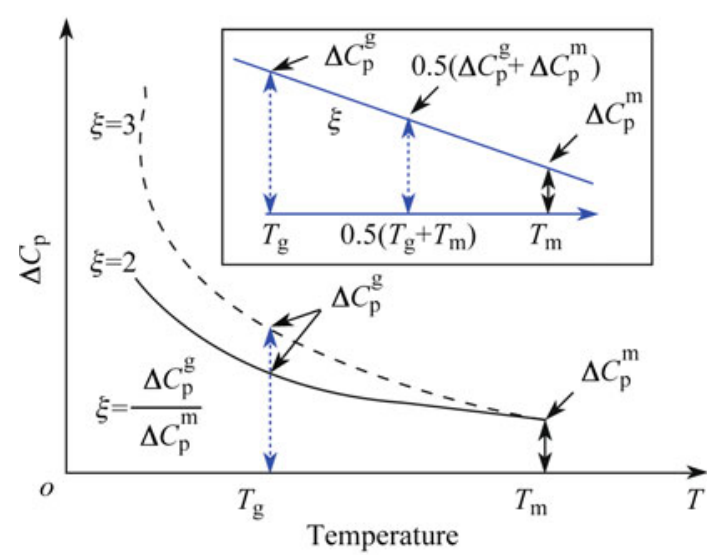

(b)

Fig. 10 Graphs of $C_{\mathrm{p}}$ a and $\Delta C_{\mathrm{p}} \mathbf{b}$ for $\xi=2$ and $\xi=3$, respectively (The inset shows the fit of the linear expression for $\Delta C_{\mathrm{p}}$ at different $\xi$ values in the temperature range from $T_{\mathrm{g}}$ to $T_{\mathrm{m}}$ )

expression closely approximate experimental values for $\Delta C_{\mathrm{p}}$ (see Fig. 3). Thus, for temperature of $0.5\left(T_{\mathrm{g}}+T_{\mathrm{m}}\right)$, a calculated value closely fits to the experimental $\Delta C_{\mathrm{p}}$, $\Delta C_{\mathrm{p}}^{0.5\left(T_{\mathrm{g}}+T_{\mathrm{m}}\right)}(\exp$.$) , can be expressed as (see Fig. 10b)$

$\Delta C_{\mathrm{p}}^{0.5\left(T_{\mathrm{g}}+T_{\mathrm{m}}\right)}(\exp )=.\frac{\Delta C_{\mathrm{p}}^{\mathrm{g}}+\Delta C_{\mathrm{p}}^{\mathrm{m}}}{2}=\frac{1+\xi}{2} \Delta C_{\mathrm{p}}^{\mathrm{m}}$.

Substitution of $T_{\max }$ into Eqs. (1) and (15), the hyperbolic expression and Dubey's expression for $\Delta C_{\mathrm{p}}$, $\Delta C_{\mathrm{p}}^{0.5\left(T_{\mathrm{g}}+T_{\mathrm{m}}\right)}$ (hyper.) and $\Delta C_{\mathrm{p}}^{0.5\left(T_{\mathrm{g}}+T_{\mathrm{m}}\right)}$ (Dubey) can be deduced as

$\Delta C_{\mathrm{p}}^{0.5\left(T_{\mathrm{g}}+T_{\mathrm{m}}\right)}$ (hyper. $)=\left(\sigma_{\mathrm{h}}-1+\frac{2-\sigma_{\mathrm{h}}}{0.5\left(1+T_{\mathrm{rg}}\right)}\right) \Delta C_{\mathrm{p}}^{\mathrm{m}}$,

$\Delta C_{\mathrm{p}}^{0.5\left(T_{\mathrm{g}}+T_{\mathrm{m}}\right)}($ Dubey $)=\frac{\Delta C_{\mathrm{p}}^{\mathrm{m}}}{\left(0.5\left(1+T_{\mathrm{rg}}\right)\right)^{2}} \exp \left(-\sigma_{\mathrm{D}} \frac{1-T_{\mathrm{rg}}}{1+T_{\mathrm{rg}}}\right)$. 


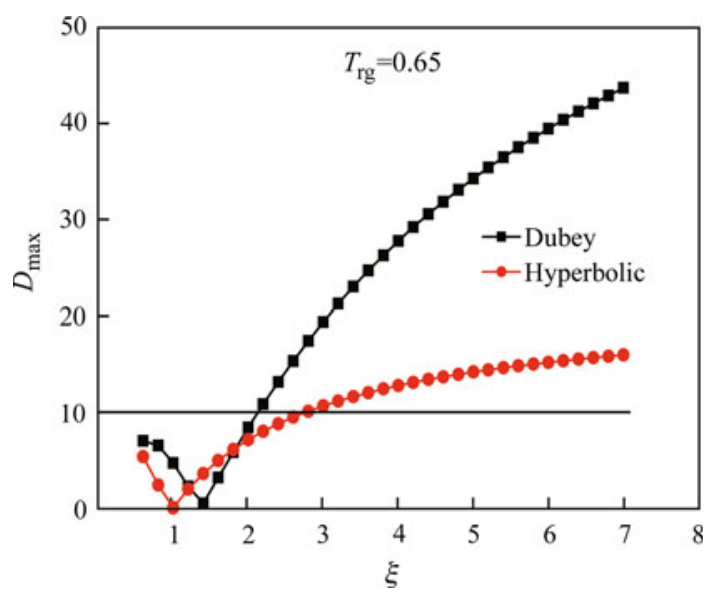

Fig. 11 Relationship between $D_{\max }$ from the hyperbolic expression and Dubey's expression for $\Delta C_{\mathrm{p}}$ and the $\xi$ parameter for $T_{\mathrm{rg}}=0.65$ using Eqs. (25) and (26)

Thus, expressions of $D_{\max }$ (hyper.) and $D_{\max }$ (Dubey) generated by the hyperbolic expression and Dubey's expression for $\Delta C_{\mathrm{p}}$ between the calculated and experimental values, respectively, can be written as

$D_{\max }$ (hyper.) $=\left|\frac{\sigma_{\mathrm{h}}-1+\frac{2-\sigma_{\mathrm{h}}}{0.5\left(1+T_{\mathrm{rg}}\right)}}{0.5(1+\xi)}-1\right|$,

$D_{\max }($ Dubey $)=\left|\frac{\frac{1}{\left(0.5\left(1+T_{\mathrm{rg}}\right)\right)^{2}} \exp \left(-\sigma_{\mathrm{D}} \frac{1-T_{\mathrm{rg}}}{1+T_{\mathrm{rg}}}\right)}{0.5(1+\xi)}-1\right|$,

where $T_{\mathrm{rg}}$ is treated as a constant with a value of 0.65 . Figure 11 shows the relationship between $D_{\max }$ from the hyperbolic expression and Dubey's expression for $\Delta C_{\mathrm{p}}$ as well as the $\xi$ parameter based on Eqs. (25) and (26). When $\xi<2$, the majority of $D_{\max }$ (Dubey) and $D_{\max }$ (hyper.) values are less than $10 \%$, indicating that these values closely approximate the $D_{\max }-\Delta C_{\mathrm{p}}$ values in Fig. 3 . When $2<\xi<7$, the $D_{\max }$ (Dubey) values dramatically increase from $10 \%$ to $43.7 \%$, and the $D_{\max }$ (hyper.) values gradually increase from $8 \%$ to $16 \%$. These findings suggest that the accuracy of values calculated using the hyperbolic expression for $\Delta C_{\mathrm{p}}$ are higher than those calculated using Dubey's expression for $\Delta C_{\mathrm{p}}$. Thus, calculated $D_{\max }$ values (see Fig. 11) from the hyperbolic expression and Dubey's expression vary according to trends very similar to those of experimental $D_{\max }$ values (see Fig. 3). Based on the error scale determined by these findings, the expressions of $D_{\max }$ (hyper.) and $D_{\max }$ (Dubey) can be used to indicate changes in $D_{\max }-$ $\Delta C_{\mathrm{p}}$ according to the $\xi$ parameter values shown in Fig. 3 and Table 2 for all 16 examined BMGs in the current study.

\section{Conclusions}

A linear expression for $\Delta C_{\mathrm{p}}$ derived from the hyperbolic expression for $\Delta C_{\mathrm{p}}$ was deduced and used to obtain a novel expression for $\Delta G, \Delta H$, and $\Delta S$. According to the experimentally determined thermodynamic parameters of the 16 examined BMGs in the current study, more accurate calculations of $\Delta C_{\mathrm{p}}, \Delta G, \Delta H$, and $\Delta S$ were obtained using the linear, hyperbolic, and Dubey's expression for $\Delta C_{\mathrm{p}}$. These results suggest that the hyperbolic expression for $\Delta C_{\mathrm{p}}$ can be applied as a universal expression for $\Delta C_{\mathrm{p}}$, while linear and Dubey's expressions for $\Delta C_{\mathrm{p}}$ are condition-dependent. Notably, Dubey's expression for $\Delta C_{\mathrm{p}}$ also closely approximated experimental values when $\xi<2$, though values were shown to deviate from experimental values for $\xi>2$.

Acknowledgments The work described in this paper was supported by the grant from the National Natural Science Foundation of China (Grant No. 51025415).

\section{References}

1. Zallen R (1973) The physics of amorphous solids. Wiley, New York

2. Machlin E (2007) An introduction to aspects of thermodynamics kinetics relevant to materials science. Elsevier, Science or Technology Books, Amsterdam

3. Stillinger FH (1988) Supercooled liquids, glass transitions and the Kauzmann paradox. J Chem Phys 88:7818-7825

4. Turnbull D (1950) Formation of crystal nuclei in liquid metals. J Appl Phys 21:1022-1028

5. Paul A (1982) Chemistry of glasses. Chapman and Hall, London

6. Singh HB, Holz A (1983) Stability limit of supercooled liquids. Solid State Commun 45:985-988

7. Dubey KS (2010) Thermodynamic and viscous behaviour of glass forming melts and glass forming ability. AIP Conf Proc 1249:211-232

8. Singh PK, Dubey KS (2012) Thermodynamic behaviour of bulk metallic glasses. Thermochim Acta 530:120-127

9. Jones D, Chadwick G (1971) An expression for the free energy of fusion in the homogeneous nucleation of solid from pure melts. Philos Mag 24:995-998

10. Mondal K, Chatterjee UK, Murty BS (2003) Gibb's free energy for the crystallization of glass forming liquids. Appl Phys Lett 83:671-673

11. Patel TA, Pratap A (2010) Study of thermodynamic properties of $\mathrm{Pt}_{57.3} \mathrm{Cu}_{14.6} \mathrm{Ni}_{5.3} \mathrm{P}_{22.8}$ bulk metallic glass. AIP Conf Proc 1249:161-165

12. Thompson CV, Spaepen F (1979) On the approximation of the free energy change on crystallization. Acta Metall 27:1855-1859

13. Hoffman JD (1958) Thermodynamic driving force in nucleation and growth processes. J Chem Phys 29:1192-1193

14. Ji X, Pan Y (2007) Gibbs free energy difference in metallic glass forming liquids. J Non-Cryst Solids 353:2443-2446

15. Li PY, Wang G, Ding D et al (2013) Characterizing thermodynamic properties of $\mathrm{Ti}-\mathrm{Cu}-\mathrm{Ni}-\mathrm{Zr}$ bulk metallic glasses by hyperbolic expression. J Alloys Compd 550:221-225 
16. Jiang QK, Zhang GQ, Yang L et al (2007) La-based bulk metallic glasses with critical diameter up to $30 \mathrm{~mm}$. Acta Mater 55:4409-4418

17. Lu ZP, Hu X, Li Y (2000) Thermodynamics of La based La-Al$\mathrm{Cu}-\mathrm{Ni}-\mathrm{Co}$ alloys studied by temperature modulated DSC. Intermetallics 8:477-480

18. Glade SC, Busch R, Lee DS et al (2000) Thermodynamics of $\mathrm{Cu}_{47} \mathrm{Ti}_{34} \mathrm{Zr}_{11} \mathrm{Ni}_{8}, \quad \mathrm{Zr}_{52.5} \mathrm{Cu}_{17.9} \mathrm{Ni}_{14.6} \mathrm{Al}_{10} \mathrm{Ti}_{5}$ and $\mathrm{Zr}_{57} \mathrm{Cu}_{15.4-}$ $\mathrm{Ni}_{12.6} \mathrm{Al}_{10} \mathrm{Nb}_{5}$ bulk metallic glass forming alloys. J Appl Phys 87:7242-7248

19. Jiang QK, Wang XD, Nie XP et al (2008) $\mathrm{Zr}-(\mathrm{Cu}, \mathrm{Ag})-\mathrm{Al}$ bulk metallic glasses. Acta Mater 56:1785-1796

20. Busch R, Liu W, Johnson WL (1998) Thermodynamics and kinetics of the $\mathrm{Mg}_{65} \mathrm{Cu}_{25} \mathrm{Y}_{10}$ bulk metallic glass forming liquid. J Appl Phys 83:4134-4141

21. Legg BA, Schroers J, Busch R (2007) Thermodynamics, kinetics, and crystallization of $\mathrm{Pt}_{57.3} \mathrm{Cu}_{14.6} \mathrm{Ni}_{5.3} \mathrm{P}_{22.8}$ bulk metallic glass. Acta Mater 55:1109-1116
22. Li PY, Wang G, Ding D et al (2012) Glass forming ability and thermodynamics in the new $\mathrm{Ti}-\mathrm{Cu}-\mathrm{Ni}-\mathrm{Zr}$ bulk metallic glasses. J Non-Cryst Solids 358:3200-3204

23. Busch R, Kim YJ, Johnson WL (1995) Thermodynamics and kinetics of the undercooled liquid and the glass transition of the $\mathrm{Zr}_{41.2} \mathrm{Ti}_{13.8} \mathrm{Cu}_{12.5} \mathrm{Ni}_{10.0} \mathrm{Be}_{22.5}$ alloy. J Appl Phys 77:4039-4043

24. Cai AH, Chen H, Li X et al (2007) An expression for the calculation of Gibbs free energy difference of multi-component bulk metallic glasses. J Alloys Compd 430:232-236

25. Gallino I, Shah MB, Busch R (2007) Enthalpy relaxation and its relation to the thermodynamics and crystallization of the $\mathrm{Zr}_{58.5} \mathrm{Cu}_{15.6} \mathrm{Ni}_{12.8} \mathrm{Al}_{10.3} \mathrm{Nb}_{2.8}$ bulk metallic glass-forming alloy. Acta Mater 55:1367-1376

26. Fan GJ, Loffler JF, Wunderlich RK et al (2004) Thermodynamics, enthalpy relaxation and fragility of the bulk metallic glassforming liquid $\mathrm{Pd}_{43} \mathrm{Ni}_{10} \mathrm{Cu}_{27} \mathrm{P}_{20}$. Acta Mater 52:667-674 